\title{
Assessment of Antifungal Activity of Some Himalayan Foliose Lichens against Plant Pathogenic Fungi
}

\author{
Priti Tiwari $^{1,2}$, Himanshu Rai ${ }^{1}$, Dalip Kumar Upreti ${ }^{1 *}$, Suman Trivedi ${ }^{2}$, Preeti Shukla ${ }^{1}$ \\ ${ }^{1}$ Lichenology Laboratory, CSIR — National Botanical Research Institute, Lucknow, India; ${ }^{2}$ Motilal Vigyan Mahavidyalaya, Barkatul- \\ lah University, Bhopal, India. \\ Email: upretidk@rediffmail.com
}

Received July $13^{\text {th }}, 2011$; revised October $7^{\text {th }}, 2011$; accepted October $21^{\text {st }}, 2011$.

\begin{abstract}
In vitro antifungal activity of the acetone, methanol and chloroform extracts of four lichen species viz, Bulbothirx setschwanensis, Everniastrum nepalense, Heterodermia diademata, Parmelaria thomsonii were investigated against seven plant pathogenic fungi (Aspergillus flavus, A. fumigatus, Alternaria alternata, Fusarium oxysporum, F. solani, F. roseum and Penicillium citrinum) with reference to commercially available synthetic antifungal drug Ketoconazole (positive control). Lichen secondary metabolites were extracted using Soxhlet extractor and were further recovered through gentle evaporation of solvents in rotary evaporator. Antifungal activity was analysed employing Bauer-Kirby disc diffusion assay. Acetone and methanol extracts of lichenized fungi were found more effective against tested plant pathogenic fungi. Principal component analysis concluded that though, Ketoconazole was effective against four of the tested plant pathogenic fungi, acetone and methanol extracts of lichens were comparatively more effective against some broad spectrum plant pathogenic fungi (Fusarium oxysporum, F. solani, F. roseum).
\end{abstract}

Keywords: Acetone Extract, Antifungal Activity, Bauer-Kirby Disc Diffusion Assay, Foliose, Himalayan Lichen, Methanol Extract, Rotary Evaporator, Secondary Metabolites, Soxhlet Extractor

\section{Introduction}

The utilization of lichen in medicine has been cited in different pharmacopoeias of the world. During the middleages lichens figured prominently among the herbs used by medicinal practitioners [1]. Lobaria pulmonaria, Cetraria islandica, and Cladonia species are reported to be effective in the treatment of pulmonary tuberculosis [2].

Lichens synthesize a wide range of primary (polysaccharides) and secondary organic compounds that show manifold bioactivities from nematocidal, antimicrobial, cytotoxic, antimutagenic and antiproliferative to immunostimulatory effects [3-5]. Out of 700 secondary metabolites so far known from lichens 550 are unique to them [6]. The lichen extracts and their components have a distinguished antimicrobial activity [2,5,7-9]. On the other hand, it is well known that microorganisms have well developed resistance to many antibiotics. This creates enormous problems in the treatment of infectious disease, and investigators therefore seek new antimicrobial sub- stances from different sources so new sources of bioactive substances have been searched for, such as medicinal herbs, fungi and lichens [10,11].

India being a mega diversity country exhibit rich diversity of different plant groups. The medicinal properties of higher group of plants is well known from the country. However, despite of the manifold medicinal uses of lower plants by traditional and ethnic groups the medicinal potential of these plants are not studied upto a greater extent. Thus, present study was done to evaluate the in vitro anti- fungal activity of four foliose lichens Bulbothrix setschwanensis (Zahlbr.) Hale, Parmelaria thomsonii (Stirton) D.D. Awasthi, Everniastrum nepalense (Taylor) Hale, Heterodermia diademata (Taylor) D.D. Awasthi, against some common plant pathogenic fungi.

\section{Materials and Methods}

\subsection{Collection and Identification of Lichen Samples}

The lichen specimens of Bulbothrix setschwanensis (Zahlbr.) 
Hale, Parmelaria thomsonii (Stirton) D.D. Awasthi, Everniastrum nepalense (Taylor) Hale, Heterodermia diademata (Taylor) D.D. Awasthi, growing luxuriantly in temperate regions of India were collected from different locations of Pithoragarh district, Uttarakhand. The identification was done morpho-anatomically using a Labomed $^{\mathrm{TM}}$ stereomicroscope and Leica ${ }^{\mathrm{TM}}$ DM 500 optical microscope and chemically with the help of thin-layer chromatography $[12,13]$. Identification was done using relevant key and monographs $[14,15]$. The voucher specimens were deposited at the lichen herbarium (LWG), National Botanical Research Institute (NBRI), Lucknow, India.

\subsection{Extraction from Lichen Sample}

Lichen samples were sorted, cleaned of substratum and dried for extraction. Three different solvent systems i.e. acetone, methanol and chloroform were used for extraction. Lichen substances were extracted using Soxhlet extractor equipped with a reflux condenser $[16,17]$ in selected solvents (acetone, methanol and chloroform) and further recovered through gentle removal of solvents from lichen samples by evaporation using rotary evaporator (Büchi Rotavapor R-200 ${ }^{\mathrm{TM}}$ ). The solvent extraction was carried out at the specific boiling temperature of the solvents (acetone- $56^{\circ} \mathrm{C}$, methanol- $65^{\circ} \mathrm{C}$ and chloroform $-61.2^{\circ} \mathrm{C}$ ) for $48 \mathrm{~h}$ for complete extraction of secondary compounds.

\subsection{Microorganisms and Media}

Seven fungal strains were procured from the mycological collection maintained by the Mycological Laboratory within the Department of microbiology Kanpur University. The fungi used as test organisms were: Aspergillus flavus, Aspergillus fumigatus, Alternaria alternata, Fusarium oxysporum, Fusarium solani, Fusarium roseum and Penicillium citrinum. Fungal cultures were maintained on Potato Dextrose agar (PDA) and were transferred to Sabourad dextrose agar for experimental purposes.

\subsection{Determination of Antimicrobial Activity}

The antimicrobial activity of lichen extracts against test fungi was determined employing disk diffusion method [18-21]. Fungi strains were inoculated on potato dextrose agar plate $\left(10^{8}\right.$ spores $\left./ \mathrm{ml}\right)$ in triplicate.

Test solutions of lichen substances were prepared by dissolving recovered lichen substances in $10 \mathrm{ml}$ of their respective solvents. Experimental diffusion discs were prepared by loading five milliliters of lichen extract, $1 \mathrm{ml}$ in each load on filter paper disks (6 $\mathrm{mm}$ in diameter), allowing the solvent to evaporate between each loading and leaving the lichen extracts on disk without the solvent. All the three lichen extracts (i.e. acetone, methanol and chloroform) were loaded in this manner. Loaded discs were planted on test plant pathogenic fungi culture plate in triplicate. Commercially available synthetic antifungal drug Ketoconazole was used as positive control. The plates were incubated for 5 days at $20^{\circ} \mathrm{C}$ to $25^{\circ} \mathrm{C}$. Growth was evaluated visually by comparing a particular plate with the negative control plates (having only plant pathogenic fungi). The antimicrobial activity was evaluated by measuring the inhibition zone diameter (in millimeter) observed (National Committee for Clincal Laboratory Standards Nccls Document [22]).

\subsection{Data Analysis}

Indirect gradient ordination method, principal component analysis (PCA) was used to summarise the effect of three solvent extracts of test lichens on test plant pathogenic fungi with reference to positive control Ketoconazole [23, 24]. PCA was done on the basis of inhibition zone $(\mathrm{mm})$ produced on test fungi colonies, utilizing correlation matrix, using multivar option in PAST $2.09[25,26]$.

\section{Results}

\subsection{General Patterns of Antifungal Activity}

Disc diffusion assay of the crude extracts of all the four lichens Bulbothrix setschwanensis, Parmelaria thomsonii, Heterodermia diademata and Everniastrum nepalense showed antifungal activity against most of the tested fungi (Figures 1 and 2). A differential activity of the three extracts (i.e. Acetone, Methanol and Chloroform) was observed. Among the three acetone and methanol extracts were more effective than the chloroform extract.

Lichen extract in acetone was found more effective in Bulbothrix setschwanensis, Parmelaria thomsonii and Heterodermia diademata, whereas in Everniastrum nepalense methanol extract was found more effective than other solvents. Positive control Ketoconazole was ineffective in case of Fusarium roseum, Fusarium solani and Fusarium oxysporum whereas lichen extracts were found active against these pathogens. The chloroform extracts of all the four lichens though were sporadically more effective than some extracts but overall Chloroform extracts were not as effective as acetone and methanol extracts.

The acetone and methanol extracts of Bulbothrix setschwanensis showed activity against Fusarium roseum and Fusarium solani while the chloroform extract and the positive control Ketoconazole exhibited no activity. The methanol extract of Bulbothrix setschwanensis showed maximum zone of inhibition of $15 \mathrm{~mm}$ while the Ketoconazole exhibited $20 \mathrm{~mm}$ zone of inhibition against Penicillium citrinum. The chloroform extract exhibited no activity against Fusarium solani, Fusarium roseum and Alternaria alternata. 

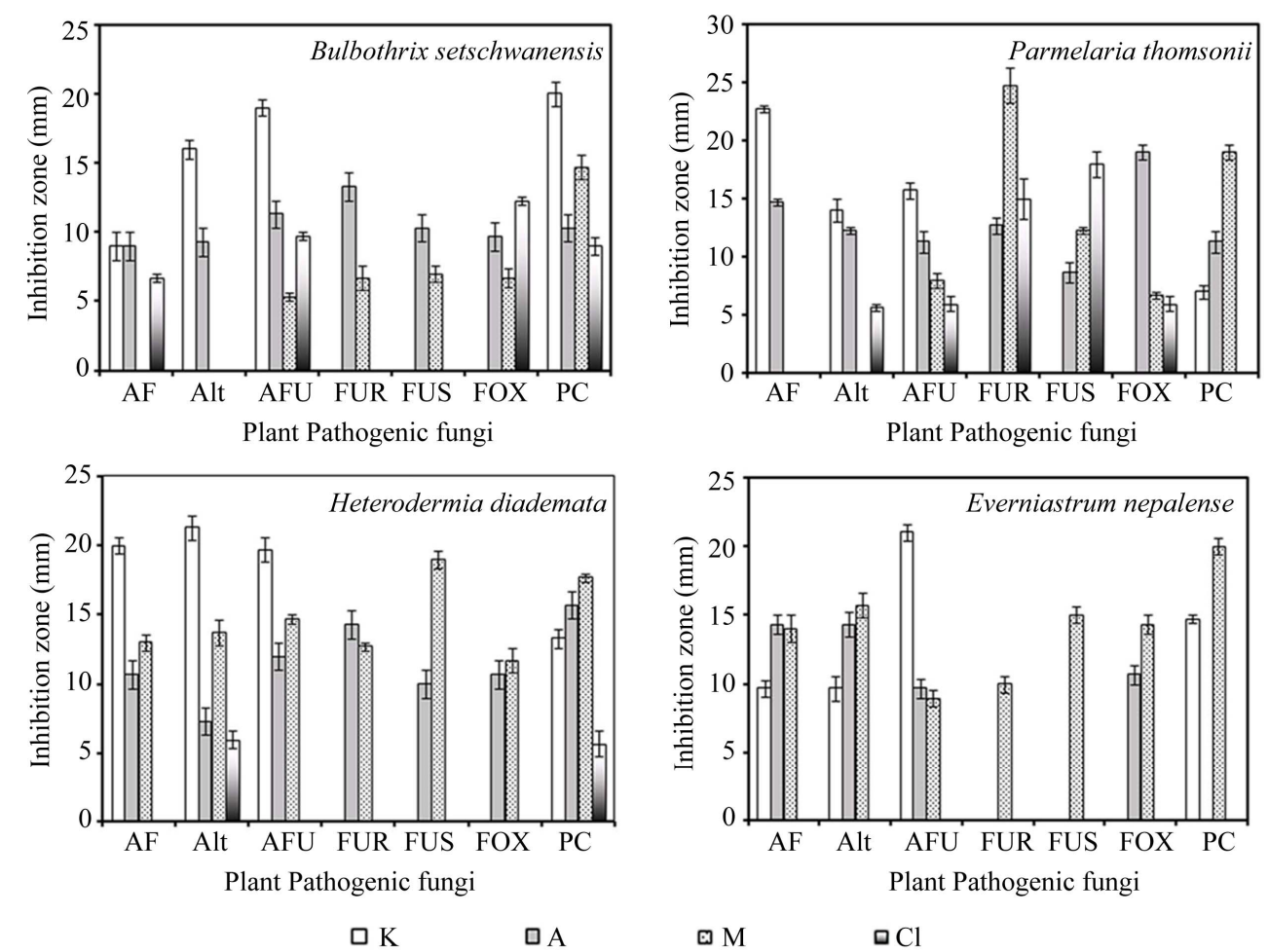

Figure 1. Results of comparative antifungal screening of the different solvent extracts $(\mathrm{A}=\mathrm{Acetone}, \mathrm{M}=\mathrm{Methanol}$, and $\mathrm{Cl}=$ Chloroform) of Himalayan foliose lichens and commercially available fungicide Ketoconazole(K), against selected plant pathogenic fungi $(\mathrm{AF}=$ Aspergillus flavus, Alt $=$ Alternaria alternata, AFU $=$ Aspergillus fumigatus, $\mathrm{FUR}=\mathrm{Fusarium}$ roseum, FUS = Fusarium soloni, FOX $=$ Fusarium oxysporum, and PC $=$ Penicilium citrinum). Reported values are in Arithmetic mean \pm Standard error.

The acetone extracts of Parmelaria thomsonii were active against all the seven tested fungi. Though all the three lichen extracts in acetone methanol and chloroform exhibited inhibition zones of $19 \mathrm{~mm}, 7 \mathrm{~mm}$ and $6 \mathrm{~mm}$ respectively, the positive control showed no antifungal activity against Fusarium oxysporum. The maximum zone of inhibition $24 \mathrm{~mm}$ exhibited by methanol extract of Parmelaria thomsonii against Fusarium roseum was better than Ketoconazole. No activity was recorded by Methanol and chloroform extracts against Aspergillus flavus, Alternaria alternata and Penicillium citrinum.

Acetone and methanol extracts of Heterodermia diademata were active against all the seven tested fungi while the chloroform extract showed activity against only two pathogenic fungi Alternaria alternata and Penicillium citrinum. The maximum zone of inhibition $19 \mathrm{~mm}$ was exhibited by methanol extract.

The methanol extracts of Everniastrum nepalense showed antifungal activity against all the tested fungi, while acetone extract exhibited activity against only four pathogenic fungi. Maximum zone of inhibition $20 \mathrm{~mm}$ was showed by methanol extract which is better than the inhibitory zone of Ketoconazole $15 \mathrm{~mm}$ against Penicillium citrinum.

\subsection{Principal Component Analysis (PCA)}

PCA analysis required four components (axis) to account for $100 \%$ variance in dataset for all the four lichenized fungi. The first two components (axis) of PCA explained maximum variation (Bulbothrix setschwanensis-72\%; Parmelaria thomsonii-83\%; Heterodermia diademata-70\%; Everniastrum nepalense-90\%) and were taken into account in the study (Figure 3). PCA biplots concluded that though positive control Ketoconazole showed higher degree of antifungal activity against some of the plant pathogenic fungi (Alternaria alternata, Aspergillus flavus, Aspergillus fumigatus and Penicillium citrinum), the lichen extracts were more effective against broad spectrum plant pathogenic fungi (Fusarium oxysporum, F. roseum, F. soloni (Figure 3).

\section{Discussion}

Bioactive compounds in recent past are gaining edge over traditionally known drugs because of their improved effectiveness against pathogens, the lichen compounds are not an exception in this field [27]. Extracts of lichen thalli proved to have strong antifungal activity against various plant pathogenic fungi $[9,28]$. 


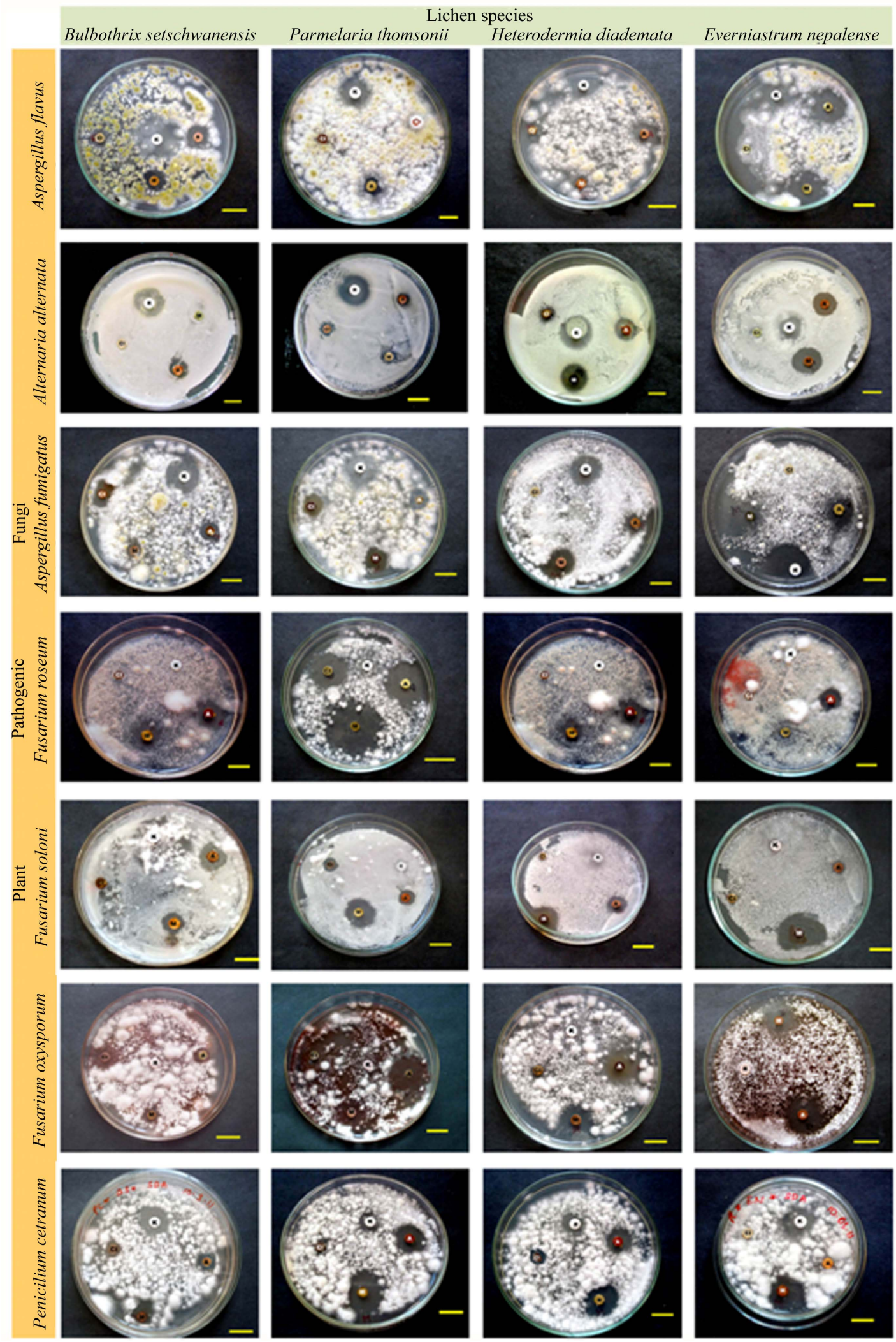

Figure 2. The inhibition zones of tested lichen extracts $(\mathrm{A}=$ Acetone, $\mathrm{M}=$ Methanol and $\mathrm{Cl}=\mathrm{Chloroform})$ against selected plant pathogenic fungi and commercially available fungicide Ketoconazole (K). Bar = 10 mm. 

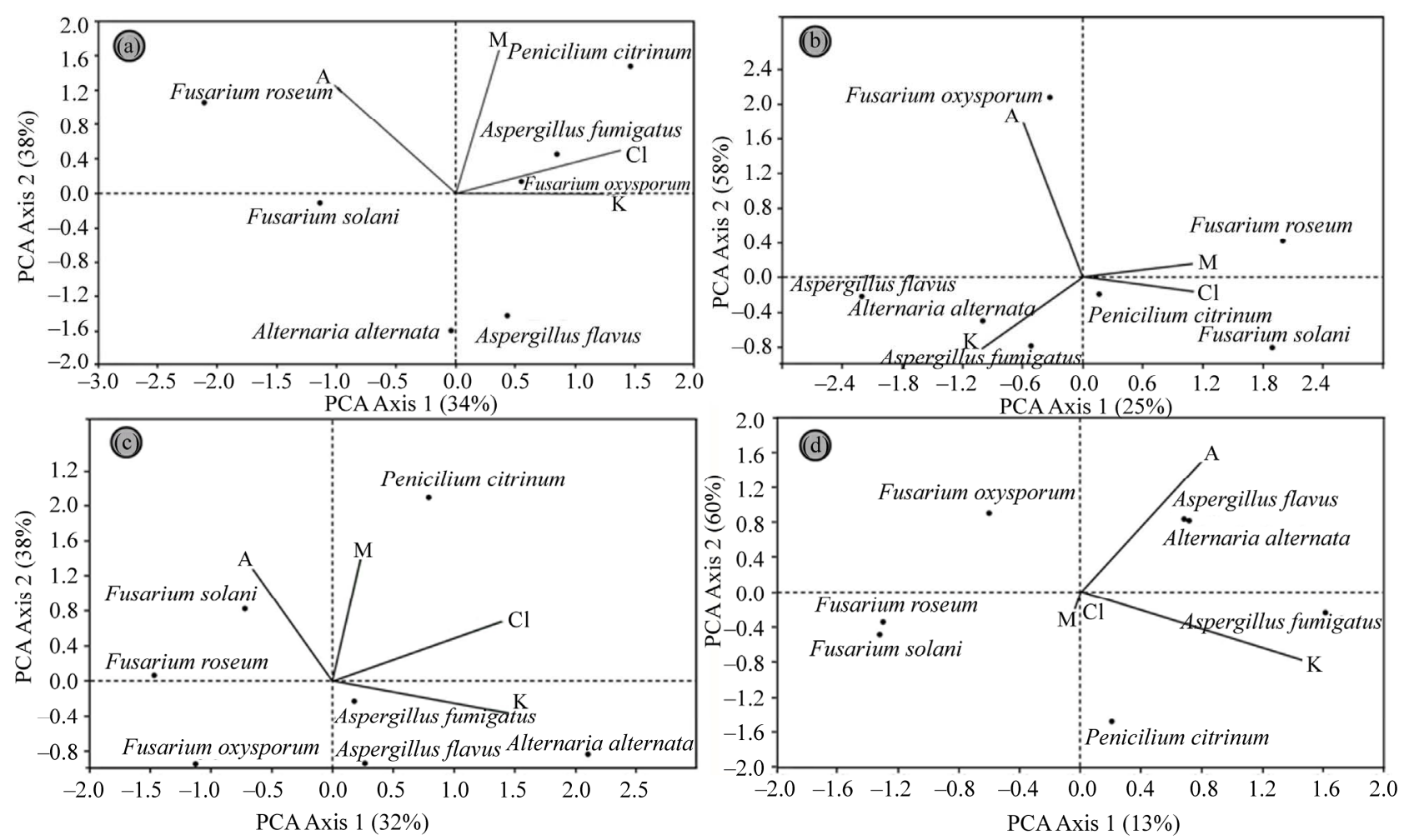

Figure 3. PCA Biplots of selected lichen $((\mathbf{a})=$ Bulbothrix setschwanensis, $(\mathrm{b})=$ Parmelaria thomsonii, $(\mathrm{c})=$ Heterodermia diademata $(\mathrm{d})=$ Everniastrum nepalense $)$ extracts $(\mathrm{A}=$ Acetone, $\mathrm{M}=$ Methanol, $\mathrm{Cl}=$ Chloroform $)$ and commercially available fungicide Ketoconazole(K) on different plant pathogenic fungi.

The present study with different solvent extracts of Bulbothrix setschwanensis, Parmelaria thomsonii, Heterodermia diademata and Everniastrum nepalense showed promising results against some well known plant pathogenic fungi. The selective antifungal effect of acetone and methanol extracts of test lichens over chloroform extracts can be attributed to the presence of different constituent secondary metabolites in lichen thalli $[28,29]$.

The better performance of lichenic extracts against commercially available antifungal Ketoconazole against some (Fusarium roseum, Fusarium solani and Fusarium oxysporum) plant pathogenic fungi suggests their superior potentials as fungicides.

\section{Acknowledgements}

Authors are thankful to the Director, National Botanical Research Institute (CSIR), Lucknow for providing necessary laboratory facilities. This research work is dedicated to Late Dr. D.D. Awasthi (28 Sept. 1922-21 Aug. 2011) pioneer Lichenologist, whose work laid foundation for systematic lichenological research in Indian subcontinent.

\section{REFERENCES}

[1] M. E. Hale, "The Biology of Lichens," 3rd Edition, Edward Arnold Ltd., London, 1983.
[2] K. O. Vartia, "Antibiotics in Lichens," In: V. Ahmadjian and M. E. Hale, Eds., The Lichens, Academic Press, New York, 1973, pp. 547-561.

[3] D. Fahselt, "Secondary Biochemistry of Lichens," Symbiosis, Vol. 16, No. 2, 1994, pp. 117-165.

[4] K. Müller, "Pharmaceutically Relevant Metabolites from Lichens," Applied Microbiology and Biotechnology, Vol. 56, No. 1-2, 2001, pp. 9-12. doi:10.1007/s002530100684

[5] K. Ingolfsdöttir, G. A. C. Chung, S. R. Gissurarson, V. G. Skulason and M. Vilhelmsdottir, "In vitro Antimycobacterial Activity of Lichen Metabolites," European Journal of Pharmaceutical Sciences, Vol. 6, No. 2, 1998, pp. 141144. doi:10.1016/S0928-0987(97)00078-X

[6] J. A. Elix and E. Stocker-Worgotter, "Biochemistry and Secondary Metabolites," In: T. H. Nash III, Ed., Lichen biology, Cambridge University Press, Cambridge, 2008, pp. 104-133. doi:10.1017/CBO9780511790478.008

[7] B. Ranković and M. Mišić, "Antifungal Activity of Extract of the Lichens Alectoria Sarmentosa and Cladonia Rangiferina," Mikologijai Fitopatologija, Vol. 41, 2007, pp. 276-281.

[8] K. Ingólfsdóttir, G. F. Gudmundsdóttir, H. M. Ögmundsdóttir, K. Paulus, S. Haraldsdóttir, H. Kristinsson and R. Bauer, "Effects of Tenuiorin and Methyl Orsellinate from the Lichen Peltigera leucophlebia on 5-/15-Lipoxygensases and Proliferation of Malignant Cell Lines in Vitro," Phytomedicine, Vol. 9, 2002, pp. 654-658. 


\section{doi:10.1078/094471102321616481}

[9] M. Gulluce, A. Aslan, M. Sokmen, F. Sahin, A. Adiguzel, G. Agar and A. Sokmen "Screening the Antioxidant and Antimicrobial Properties of the Lichens Parmelia saxatilis, Platismatia glauca, Ramalina pollinaria, Ramalina polymorpha and Umbilicaria nylanderiana," Phytomedicine, Vol. 13, No. 7, 2006, pp. 515-521. doi:10.1016/i.phymed.2005.09.008

[10] I. Karaman, F. Sanin, M. Güllüce, H. Ogütcü, M. Sengul and A. Adigüzel, "Antimicrobial Activity of Aquaeos and Methanol Extracts of Juniperus oxicedrus," Journal of Ethnopharmacology, Vol. 37, No. 2-3, 2003, pp. 1-5.

[11] K. Hostettmann, L. Wolfender and S. Rodriguez, "Rapid Detections and Subsequent Isolation of Bioactive Constituents of Crude Plant Extracts," Planta Medica, Vol. 63, No. 1, 1987, pp. 2-10. doi:10.1055/s-2006-957592

[12] A. Orange, P. W. James and F. J. White, "Microchemical Methods for the Identification of Lichen Products," British Lichen Society, Edinburgh, 2001.

[13] J. A. Elix and J. L. Ernst-Russel, "A Catalogue of Standar- dized Thin Layer Crhomatographic Data and Biosynthetic Relationships for Lichen Substances," 2nd Edition, Australian National University, Canberra, 1993.

[14] D. D. Awasthi, "A Compendium of the Macrolichens from India, Nepal and Sri Lanka," Bishen Singh Mahendra Pal Singh, Dehra-Dun, 2007.

[15] P. K Divakar and D. K Upreti, "Parmelioid Lichens in India: A Revisionary Study," Bishen Singh Mahendra Pal Singh., Dehra-Dun, 2005.

[16] F. Soxhlet, "Die Gewichtsanalytische Bestimmung des Milchfettes," Polytechnisches Journal, Vol. 232, 1879, pp. 461-465.

[17] L. M. Harwood and C. J. Moody, "Experimental Organic Chemistry: Principles and Practice," Illustrated Edition, Blackwell Scientific, Oxford, 1989.

[18] A. W. Bauer, D. M. Perry and W. M. M. Kirby, "Single Disc Antibiotic Sensitivity Testing of Staphylococci," Achieve of Internal Medicine, Vol. 104, No. 2, 1959, pp. 208-216.
[19] A. W. Bauer, W. M. M. Kirby, J. K. C. Scherris and M. Turck, "Antibiotic Susceptibility Testing by a Standardized Single Disc Method," American Journal of Clinical Pathology, Vol. 45, No. 4, 1966, pp. 493-496.

[20] J. M. Larkin, "A Laboratory Manual for Microbiology," 3rd Edition, Kendal/Hunt Publishing Company, San Francisco, 1982.

[21] W. M. M. Kirby, G. M. Yoshihara, K. Sundstedt and J. Warren, "Clinical Usefulness of a Single Disc Method for Antibiotic Sensitivity Testing," Antibiotics Annual 19561957, Antibiotica, Inc., New York, 1957, p. 892.

[22] National Committee for Clincal Laboratory Standards, NCCLS Document 1997, M26-P Villanova.

[23] C. J. F. ter Braak and I. C. Prentice, "A Theory of Gradient Analysis," Advances in Ecological Research, Vol. 18 1988, pp. 271-313. doi:10.1016/S0065-2504(08)60183-X

[24] H. G. Gauch Jr., "Multivariate Analysis in Community Structure," Cambridge University Press, Cambridge, 1982.

[25] Ø. Hammer, D. A. T. Harper and D. P. Ryan, "PAST: Paleontological Statistics Software Package for Education and Data Analysis," Palaentologia Electonica, Vol. 4, 2001, pp. 1-9.

[26] P. Tiwari, H. Rai, D. K. Upreti, S. Trivedi and P. Shukla, "Antifungal Activity of a Common Himalayan Foliose Lichen Parmotrema tinctorum (Despr. ex Nyl.) Hale," Nature and Science, Vol. 9, No. 9, 2011, pp. 167-171.

[27] S. Huneck, "The Significance of Lichens and Their Metabolites," Naturwissenschaften, Vol. 86, No. 12, 1999, pp. 559-570. doi:10.1007/s001140050676

[28] P. Halama and C. Van Haluwin, "Antifungal Activity of Lichen Extracts and Lichenic Acids," Biocontrol, Vol. 49, No. 1, 2004, pp. 95-107. doi:10.1023/B:BICO.0000009378.31023.ba

[29] M. Goel, P. Dureja, A. Rani, P. L. Uniyal and H. Laatsch, "Isolation, Characterization and Antifungal Activity of Major Constituents of the Himalayan Lichen Parmelia reticulata Tayl.," Journal of Agriculture and Food Chemistry, Vol. 59, No. 6, pp. 2299-2307. 